IZA DP No. 7693

Seasonality in Smoking Behaviour: Re-evaluating the Effects of the 2005 Public Smoking Ban in Italy

Emilia Del Bono

Klaus Grünberger

Daniela Vuri

October 2013 


\title{
Seasonality in Smoking Behaviour: Re-evaluating the Effects of the 2005 Public Smoking Ban in Italy
}

\author{
Emilia Del Bono \\ ISER, University of Essex \\ and IZA \\ Klaus Grünberger \\ University of Rome "Tor Vergata" \\ Daniela Vuri \\ University of Rome "Tor Vergata", \\ CEIS and IZA
}

Discussion Paper No. 7693

October 2013

\author{
IZA \\ P.O. Box 7240 \\ 53072 Bonn \\ Germany \\ Phone: +49-228-3894-0 \\ Fax: +49-228-3894-180 \\ E-mail: iza@iza.org
}

Any opinions expressed here are those of the author(s) and not those of IZA. Research published in this series may include views on policy, but the institute itself takes no institutional policy positions. The IZA research network is committed to the IZA Guiding Principles of Research Integrity.

The Institute for the Study of Labor (IZA) in Bonn is a local and virtual international research center and a place of communication between science, politics and business. IZA is an independent nonprofit organization supported by Deutsche Post Foundation. The center is associated with the University of Bonn and offers a stimulating research environment through its international network, workshops and conferences, data service, project support, research visits and doctoral program. IZA engages in (i) original and internationally competitive research in all fields of labor economics, (ii) development of policy concepts, and (iii) dissemination of research results and concepts to the interested public.

IZA Discussion Papers often represent preliminary work and are circulated to encourage discussion. Citation of such a paper should account for its provisional character. A revised version may be available directly from the author. 
IZA Discussion Paper No. 7693

October 2013

\section{ABSTRACT}

\section{Seasonality in Smoking Behaviour: Re-evaluating the Effects of the 2005 Public Smoking Ban in Italy}

This paper investigates the impact of the public smoking ban which came into effect in Italy on January 2005 on individual smoking behaviour. Current empirical evidence supports the existence of a negative effect of the Italian ban on smoking prevalence and consumption in the general population. This is in contrast to what has been found in some other European countries. Our analysis shows that the apparent success of the Italian smoking ban is due to the fact that existing results do not take into account seasonal differences in smoking behaviour. Using quarterly data from the 1999/2000 and 2004/2005 Italian Health Surveys and adopting a difference-in-difference approach that nets out monthly variation in smoking rates, we show that the Italian smoking ban had no impact on individual smoking behaviour for the population as a whole, and only small effects on some groups of individuals.

JEL Classification: I12, I18, K32, C31

Keywords: smoking, cigarette consumption, public smoking ban, treatment effects

Corresponding author:

Daniela Vuri

Department of Economics and Finance

University of Rome "Tor Vergata"

Rome

Italy

E-mail: daniela.vuri@uniroma2.it

\footnotetext{
${ }^{*}$ We are grateful to the Ministry of Health for providing the data. We thank seminar participants at Lech am Arlberg Labor Economics Seminar 2013 (Vienna) and at the PhD Lunch seminar (Tor Vergata University) for helpful comments. The authors are responsible for all errors and omissions.
} 


\section{Introduction}

The increased awareness of the damage caused by tobacco smoking has led numerous countries to prohibit tobacco advertising and introduce partial or total bans on smoking in workplaces and most recently - in all public areas. The main rationale behind these policies is that smoking bans reduce non-smokers' exposure to second hand smoking and at the same time create a supportive environment for those who want to quit or decrease their tobacco consumption. ${ }^{1}$

Several studies investigate the effect of smoking bans on smoking or its health consequences. Recent epidemiological evidence shows that public smoking bans in some US states and European countries have significantly reduced acute myocardial infarctions and asthma exacerbations (Barone-Adesi et al., 2006; Juster et al., 2007; Pell et al., 2008), with some positive effects on birth outcomes (Mackay et al., 2012). What appears to be less clear-cut, however, is whether public smoking bans have had a significant impact on individual smoking behaviour. ${ }^{2}$ In Spain, Guerrero et al. (2011) find a lower than expected smoking prevalence one year after the implementation of a partial smoking ban. Evidence for Scotland shows a significant reduction in smoking prevalence 3-6 months before a law banning smoking in public places came into force (Mackay et al., 2011). By contrast, studies conducted in England (Elton and Campbell, 2008; Lee et al., 2001), the Netherlands (Verdonk-Kleinjan et al., 2011), Germany (Anger et al., 2011) and Ireland (Mullally et al., 2009) find no significant impact of smoking bans on smoking prevalence in the general population.

In this paper we investigate the impact of the smoking ban in public places introduced in 2005 in Italy on individual smoking prevalence and cigarette consumption. Italy was one of the first European countries to enact a comprehensive and strict regulation of smoke-free areas. ${ }^{3}$ As from

\footnotetext{
${ }^{1}$ Tobacco smoking is a well-known cause of several diseases, including lung cancer and cardiovascular and respiratory diseases (Doll et al., 1994). Cigarette smoking is also considered the single most important modifiable factor affecting birth weight and the risk of preterm birth (Shiono and Behrman, 1995). Growing evidence indicates that both active and passive smoking affect cardiac problems (Barnova et al., 2005; Law et al., 1997; Raupach et al., 2006) and increase the severity of asthma as well as the probability of developing this condition in adulthood (Stapleton et al., 2011).

${ }^{2}$ Early studies in economics investigated the effect on smoking prevalence of workplace bans and found that these significantly reduced smoking prevalence and consumption among employed smokers (Evans et al., 1999; Fichtenberg and Glantz, 2000). However, bans on smoking in public places are intrinsically different from workplace bans in several respects. For example, a smoker will generally have more discretion over time spent in hospitality premises than over time spent in the workplace.

${ }^{3}$ After Norway and Malta in 2004.
} 
10 January 2005 the Italian government banned smoking in all indoor public places, including cafés, restaurants, airports, railway stations, as well as all public and private workplaces. Public support for the ban was widespread and enforcement was considered successful (Gallus et al., 2006; Gorini 2011). The existing empirical evidence strongly supports a negative short-run effect of the public smoking ban on both smoking prevalence and total consumption of cigarettes (Buonanno and Ranzani, 2013; Cesaroni et al., 2008; Federico et al., 2012; Gallus et al., 2006; Gallus et al., 2007). However this evidence is mainly based on small and non-representative samples of the population or on before-after comparisons without a valid control group.

We show that the existing evaluation results for Italy are not robust to alternative identification strategies. In particular we document the existence of significant seasonal patterns in smoking intensity and smoking rates using official data on tobacco sales (ISTAT, 2004-2010) as well as microdata from the Italian Health Surveys over various years. We show that ignoring seasonal effects leads to overestimate the impact of the reform. In order to account for seasonal variation in smoking behaviour we apply a difference-in-difference approach using quarterly data from the 1999/2000 and 2004/2005 Italian Health Surveys.

Our study sheds light on a previously overlooked phenomenon: the existence of a seasonal pattern in smoking consumption. We examine this pattern using both aggregate data on cigarette sales and monthly data on individual smoking prevalence and consumption. We discuss possible reasons for the presence of seasonal effects in smoking, including tax increases, weather conditions and timing of quitting efforts (e.g., New Year's resolutions). We show that accounting for seasonality in smoking behaviour dramatically affects previous evaluations of the smoking ban effects in Italy. As shown in other contexts (Anger et al., 2011), we find that the response to the ban was highly heterogeneous across the population, and that even in the short-term the effects on smoking prevalence and consumption were restricted to specific subgroups. This analysis has important implications for the evaluation of smoking regulations introduced in many European countries in recent years. Most importantly, our results suggest that in the presence of seasonal variation in the outcome variable a before/after approach might lead to biased estimates of the effects of interest and that using a short window of time around the cut-off date is no panacea. 


\section{The 2005 ban on smoking in public places in Italy}

On 10 January 2005 a total ban on smoking in public places came into effect in Italy. ${ }^{4}$ The ban prohibited smoking from enclosed workplaces and hospitality premises, including bars, cafés, restaurants and clubs. Special smoking rooms were allowed, but under strict conditions. ${ }^{5}$ Fines for transgressors were set within the range of 27.5 to 275 euros and were 10 times higher for restaurant and café owners, who were considered responsible for enforcing the law.

The ban received wide support both before and after its implementation (Gallus et al., 2004; Gallus et al., 2006; La Vecchia et al., 2001). According to a survey conducted in 2008, Italians were the Europeans most in favor of a national smoking ban (88\%) (Gorini, 2011). Enforcement controls showed that compliance was good, with fewer than 100 (1.5\%) violations in about 6,000 checks by the police (Gallus et al. 2006). Various national surveys indicated that $80-90 \%$ of those interviewed thought the ban was observed in most hospitality premises (e.g., Tramacere et al., 2009).

Several pieces of evidence suggest that the Italian ban was successful at reducing passive as well as active smoking. Official legal sales of cigarettes dropped to 28.3 million $\mathrm{kg}$ in the period between January and April 2005, compared to 31.1 million $\mathrm{kg}$ in the corresponding period of 2004; a decline of $8.9 \%$. A survey carried out in randomly selected pubs and clubs before and after January 2005 found reductions in nicotine vapour phase concentration of about $90-95 \%$ (Gorini et al. 2005). Barone-Adesi et al. (2006) find a significant decline in rates of hospital admission for acute myocardial infarction among individuals under 60 (11\%), while Cesaroni et al. (2008) document a $4 \%$ decline in acute coronary events in the population under 70 . Using data from a nationally representative survey on smoking behaviour conducted in 2004 and 2005, Gallus et al. (2006) report a significant decline in both smoking prevalence (2.3\%) and cigarette consumption (5.5\%), which was particularly pronounced among women and young people.

Although some of this evidence is based on small samples (e.g., the survey used in Gallus et al. 2006 has about 3,100 individuals), two recent studies by Federico et al. (2012) and Buonanno and

\footnotetext{
${ }^{4}$ The law was passed on 16 January 2003 (the so-called "Legge Sirchia"), but came into effect only 2 years later.

${ }^{5}$ These rooms had to be physically separated from the non-smoking areas, provided with continuous floor-to-ceiling walls and a ventilation system. In practice, only $1-2 \%$ of all hospitality premises offered smoking rooms (Gorini et al., 2011).
} 
Ranzani (2013) also report statistically significant effects on individual smoking behaviour based on data from large and representative national surveys. Federico et al. (2012) analyse 11 waves from the Multiscopo Survey (conducted by the Italian Office of National Statistics, ISTAT, with a sample size of about 30,000 observations for each year), from 1999 to 2010 and show evidence of a decrease in smoking prevalence for men $(2.6 \%)$ as well as an increase in quit rates for both men $(3.3 \%)$ and women $(4.5 \%)$ in the year immediately after the introduction of the ban. Similarly, Buonanno and Ranzani (2013) show that in Italy smoking prevalence decreased by $1.3 \%$ and number of cigarettes smoked declined by almost $8 \%$ as a consequence of the introduction of the smoking ban. Their analysis is based on a sample of more than 120,000 individuals from the 2004-2005 Italian Health Survey (Condizioni di salute e ricorso ai servizi sanitari).

The main shortcoming of these studies is that these estimates may partially reflect seasonality in smoking behaviour. All the Multiscopo Surveys for the years up to 2004 are collected during the last months of the calendar year (mainly November), while those for the period 2005-2010 are collected during the months of February and March. Clearly, any effect of the ban identified by Federico et al. (2012) is going to confound seasonal and policy-induced variation in smoking. The study by Buonanno and Ranzani (2013) is also vulnerable to seasonal effects since their results rely on a comparison between smoking prevalence and cigarette consumption measured in December 2004 (before the ban) versus March-September 2005 (after the ban). If smoking behaviour is subject to seasonal variation - due for example to tax increases, weather conditions and timing of quitting efforts (eg, New Year's resolutions) - and smoking incidence or cigarettes consumption is highest (lowest) during the last (first) months of the year, then the effect of the ban estimated by these studies is going to be larger than the true effect. In the next section, we will propose an empirical strategy which takes into account seasonal effects in smoking behaviour and show that this leads to a very different evaluation of the effectiveness of the Italian smoking ban. 


\section{Empirical model}

In order to estimate the effects of the smoking ban, Buonanno and Ranzani (2013) analyse the 2004-2005 Italian Health Survey, which interviews individuals in December 2004 and March, June and September 2005. The effect of the smoking ban is estimated by the following regression:

$$
Y_{i t}=\alpha+\beta D_{i t}+\mu X_{i t}+u_{i t}
$$

where $Y_{i t}$ represents the smoking status or the number of cigarettes smoked by individual $i$ at time $t$, and the variable $D$ captures the effect of the ban, assuming value 0 for all individuals interviewed before January 2005 (control group) and value 1 for those interviewed afterwards (treatment group). The covariate matrix $X$ includes: age, gender, household size, presence of children below 8 years of age, marital status, educational attainment, region of residence, professional condition, an indicator for adequate/good economic resources, and an indicator of self-reported health.

The key identifying assumption of the model is that in the absence of treatment the difference in smoking behavior between individuals in the control and in the treatment groups is not statistically significant from zero. However, there are at least two plausible reasons why this assumption might not hold. The first is that we might be in the presence of long-term trends in smoking behaviour which, especially if negative, might lead to over-estimate the impact of the ban. The second problem is that smoking, like many other activities, might exhibit seasonal variation which if not taken into account might confound the effect of the ban.

Buonanno and Ranzani (2013) base their main analysis on a small interval before and after the introduction of the ban - effectively comparing smoking in March 2005 to what observed in December 2004. While this strategy might be an effective way of dealing with the presence of a long-term trend, it makes the estimate more vulnerable to the presence of seasonal effects. These might be at work due to changes in excise tax, the presence of New Year's resolutions to reduce or quit smoking, or different average temperatures in different months of the year.

In order to exclude the existence of seasonal effects, Buonanno and Ranzani (2013) look separately at data from the 1999-2000 Health Survey - which interviews individuals in December 1999 
and March, June and September 2000. They find no effect of the 2000 year dummy on any of the outcomes of interest, thus concluding that seasonality is not a concern.

A more robust strategy is to employ a difference-in-difference (DiD) approach and estimate the following equation:

$$
Y_{i t}=\alpha+\beta D_{i t}+\gamma S_{i t}+\delta D_{i t} \times S_{i t}+\mu X_{i t}+u_{i t}
$$

where $S_{i t}$ is a variable which takes value 1 if the individual is observed in 2004-2005 and value 0 if he or she is observed in 1999-2000, and $D_{i t}$ is - as previously - a dummy that takes the value 1 if the individual is interviewed in March (June or September) and 0 if he or she is interviewed in December. The coefficient $\beta$ captures differences in smoking behaviour between March (June or September) and December, independently of the year of interview, i.e. it represents seasonal effects. The coefficient $\gamma$ captures the effect on $Y$ of time, i.e. general changes in the economic and social context across the two waves. The interaction coefficient $\delta$ is the effect of interest because it captures the differential impact of the smoking ban on individuals interviewed before and after the reform net of possible seasonal effects.

In what follows we will replicate the analysis in Buonanno and Ranzani (2013) and estimate the effects of the smoking ban on smoking prevalence and cigarettes consumption for both the short and the medium term using the specification in (1). Short-term estimates will include only observations from December and March, while medium-term estimates will additionally consider individuals interviewed in the months of June and September. We will then present new estimates of the effects of the ban using the model in (2) and show that, in contrast with what previously found, the Italian smoking ban had very small and mostly insignificant effects on the vast majority of the population. First though, we discuss in more detail our data and present evidence of seasonal effects in smoking behaviour. 


\section{Our data}

The Italian Health Survey (IHS) is carried out approximately once every 5 years. In this paper we use data from the 1999/2000 and 2004/2005 waves. ${ }^{6}$ Interviews took place in the month of December of one year (1999 or 2004), and the months of March, June and September of the following year (2000 or 2005). A representative sample of households was interviewed in every month and this enables us to investigate seasonal patterns. The survey contains detailed information about the respondents' smoking status and cigarettes consumption, as well as a large amount of demographic information about the individual and the household.

After excluding people under the age of 15 and over 65, our sample size reduces to 178,472 individuals (93,853 in $1999 / 2000$ and 84,619 in 2004/2005), with more than 20,000 interviews in each month (Table 1). The data show a negative trend over time in smoking prevalence and consumption. During the period from 1999/2000 and 2004/2005 the overall percentage of smokers declined from $27.7 \%$ to $25.3 \%$, and the average number of daily cigarettes per capita decreased from from 4.08 to 3.49. Also the fraction of heavy smokers (more than 10 cigarettes per day) decreased over the period from $20.6 \%$ to $18.4 \%$. This is consistent with official data that shows that sales of cigarettes dropped from 100.4 tons in 2000 to 92.8 tons in 2005 , a decrease of $7.6 \% .^{7}$

Table 2 shows the variation in smoking behaviour by gender and individual socio-economic characteristics. There is a large gender gap in smoking. Men are almost 50\% more likely to smoke than women and those who smoke consume on average double the amount of cigarettes per day. Individuals who are not married also have a higher smoking rate than those who are married. Regional differences are relatively small for men and quite large for women - mainly because women in the South smoke considerably less than women in the rest of the country, while differences by level of education are found only among men - with higher levels of smoking among those with a low educational qualification. Age differences are quite marked, with individuals aged 40 and over exhibiting higher rates of smoking prevalence and cigarettes consumption. We also see that

\footnotetext{
${ }^{6}$ A similar survey, but with a smaller overall number of observations and a different sampling period was conducted in 1994-1995. The latest survey was conducted in 2012-2013, but the data is still not available.

${ }^{7}$ Data provided by Amministrazione Autonoma Monopoli di Stato, the government department in charge of regulating and monitoring tobacco sales (available on request).
} 
working individuals smoke considerably more than those without a job. We finally consider two smaller groups: the young (age 15-39) and not married, and the young and not employed. The former appear to have a smoking pattern similar to those of young people as a whole; while the latter show mean behaviour close to that of the non-employed group.

Figure 1 shows average smoking rates for each month in the 1999/2000 and 2004/2005 waves of the IHS. The graph for the whole sample clearly indicates that smoking incidence exhibits a seasonal pattern. Smoking is almost always more prevalent in the months of December and September than in the months of March or June. Although it is possible that the decrease in smoking rates between December 2004 and March 2005 was a consequence of the smoking ban, the fact that there was a similar decline between the months of December 1999 and March 2000 is an important piece of evidence to consider. Performing an analysis on the 2004/2005 data alone in the absence of a control group and in the presence of seasonal effects might lead to overestimate the effect of the ban. Similar considerations apply to cigarettes consumption data (Figure 2).

These graphs also indicate that women's monthly smoking patters are different from those of men, and exhibit less seasonal variation in the period preceding the implementation of the ban (1999/2000 wave). Further analysis by subgroups (defined according to age, level of education, etc.) indicates that there is substantial heterogeneity in seasonal smoking patterns. It will therefore be particularly important to examine heterogeneity in the effects of the ban as well.

The seasonal patterns in smoking shown in Figures 1 and 2 is also reflected in aggregate data on cigarettes sales shown in Figure 3 and may have several explanations. One possibility is that there might be a correlation between average temperatures and smoking, as people tend to visit hospitality venues more frequently in the spring and the summer than in the winter. ${ }^{8}$ A second possibility is that the price of cigarettes is subject to seasonal variation due to regular changes in excise duty (see Figure 4). Finally, the decline in smoking between December and March could be the result of New Year's resolutions, whereby some people might decide to quit smoking and/or adopt healthier behaviours after the end of the year. These are alternative hypotheses that we will

\footnotetext{
${ }^{8}$ In the IHS of 1999/2000 respondents reported whether they visited a discotheque in the previous quarter of the year. In December 25.1\% answered with 'yes', while in the months after, March (27.5\%), June (25.8\%) and September $(29.3 \%)$, the ratio was on average $27.5 \%$.
} 
take into account in Section 5.3.

\section{Results}

\subsection{Replication of previous findings}

The purpose of our analysis is to show that when seasonal differences in smoking behaviour are not adequately controlled for a before/after evaluation of the impact of regulation affecting smoking behaviour, such as the smoking ban in public areas introduced in Italy in January 2005, will lead to incorrect estimates of the size of the effects. In order to demonstrate this is the case, we first discuss the results obtained in the previous literature when no account is taken of seasonal effects.

The original results of Buonanno and Ranzani (2013) are reported in columns (1)-(3) of Table 3. These estimates show that the short-term effect of the ban obtained by comparing individual smoking in March 2015 against December 2004 (Panel A, first row) is negative across the whole population, with a decrease of 1.3 percentage points in smoking prevalence (or a $5.1 \%$ reduction), a 0.27 reduction in the number of cigarettes smoked (7.7\%), and a reduction of 1.3 percentage points in the incidence of heavy smokers, here identified by the proportion of people smoking more than 10 cigarettes per day (7.2\%). The medium-term effects (Panel B), obtained by comparing smoking behaviour in March, June and September 2005 against December 2004 are less pronounced, but equally statistically significant. Using the same sample restrictions and the same specification, we can replicate these results almost identically, as shown in columns (4)-(6).

Analysis by subgroups in Buonanno and Ranzani (2013) shows that the effect of the ban was relatively stronger among women than men $(6 \%$ for women and $4.2 \%$ for men, as obtained by dividing the coefficients in Table 3 by the mean prevalence by sex shown in Table 2) and mainly concentrated among married individuals and those living in the South. We find very similar results in our estimates. The main exception is that we we find stronger effects for unmarried individuals, particularly in relation to smoking prevalence. ${ }^{9}$

\footnotetext{
${ }^{9}$ We simply define this subgroups as people who are not married. Our subgroup of not married people differs from the subgroup specified by Buonanno and Ranzani (2013) in terms of number of observations. We can not find the reason for this difference.
} 
The specification used in Buonanno and Ranzani (2013) includes among the covariates: age, age squared, household size, an indicator variables for being female, the presence of children of age below 8 in the household, indicator variables for being married, having a high school diploma, being employed, being inactive, having household economic conditions which are adequate or excellent, having a discrete, good or very good self-reported health status and a full set of regional dummies. In columns (7)-(9) we report results based on a slightly different specification. Here we omit selfreported health - as it is likely to be endogenous and simultaneously determined with smoking behaviour - and use a full set of dummy variables for educational attainment (elementary school or less, junior high school diploma, high school diploma and missing information on educational attainment). Furthermore, in columns (8) and (9) we exclude from our sample individuals who smoke, but who do not provide valid information on the number of cigarettes smoked. As we can see, these changes make almost no difference to the results.

In Table 3 we also estimate the effect of the smoking ban on additional subgroups of individuals. Low educated, young, young and not married, and employed individuals are the most affected by the ban both in terms of prevalence and intensity. These results are not surprising since young and not married individuals tend to visit hospitality venues more often, while those employed should be affected due to the workplace element of the new regulations. Differences by level of education are more difficult to explain, but could be consistent with the fact that a larger proportion of low educated individuals work in the hospitality sector (in our data $20.6 \%$ of all low educated individuals are employed in this sector against $16.3 \%$ of high educated individuals). ${ }^{10}$ Overall, these estimates show that there is significant heterogeneity in the effect of the smoking ban across different subgroups of the population.

\subsection{Estimates based on a DiD approach}

We now estimate the model using the specification in equation (2), which nets out seasonal effects using the variation in smoking behaviour observed over a period not affected by the ban, i.e. the

\footnotetext{
${ }^{10}$ Previous evidence on whether the effects of smoking control policies differ by education level is scarce, with most of the analyses conducted either on the general population (e.g., Guerrero et al., 2011; MacKay et al., 2011) or on very specific subgroups (e.g., Mullally et al., 2009).
} 
months of March 2000 and December 1999. In other words, we use data from the 1999-2000 IHS to construct a 'control group'. ${ }^{11}$ We do so for the overall sample, and separately for the subsamples of men and women. Each of these samples is then divided into smaller groups, according to the individual characteristics used in Buonanno and Ranzani (2013) - namely marital status and geographic area - but also other relevant attributes, such as education, age, working status and a combination of some of them as reported in Table 3. As before, we consider both short-term effects (Table 4) and medium-term effects (Table 5).

Comparing the results in Table 3 and Table 4 it is immediately obvious that by applying a DiD strategy most of the impact of the ban found in the previous analysis is washed out. Table 4 shows that the short-run effects of the ban are much smaller in magnitude and no longer statistically significant for the overall population and for men in particular. For women there is some evidence that the negative effects of the ban on smoking are still present, although these are not always as precisely estimated as before. Similar results hold for the medium-term effects (Table 5), where we see no change in smoking incidence in the population as a whole and in male smoking behaviour, and only some effects on the smoking intensity for women.

Looking at the analysis by subgroups is very informative. There is a clear indication - much clearer than in the before/after analysis - that the effects are restricted to very specific subgroups of the population. In particular, Table 4 shows that in the short-term most of the effects are concentrated among individuals who are young and not married, or young and not working. Estimates of medium-term effects (Table 5) indicate that the ban reduced smoking also among the not married, the low-educated, and not employed individuals more generally, and that we can attribute most of these effects to the behaviour of women. The most pronounced medium-term effects, for example, are to be found for young and not married women (see Table 5), where the incidence of smoking is reduced by 2.9 percentage points $(-14.5 \%)$ and the intensity falls by almost 0.6 cigarettes a day

\footnotetext{
${ }^{11}$ We conduct extensive checks to verify that the 1999-2000 survey offers a valid 'control group' for the 2004-05 survey. In particular we test for the presence of significant differences in the characteristics (e.g., age, gender, level of education, geographic distribution, household composition and economic position, etc.) of the sample of individuals interviewed in December and March, respectively, in the two surveys. We can find none. We also test for the presence of statistically significant differences in the December vs. March change in these characteristics across surveys (in the spirit of our DiD empirical specification). Again, we cannot see any significant change in the underlying composition of the sample. These checks are available upon request.
} 
$(-28.9 \%)$. Moreover, also the group of young and not employed women is greatly affected by the ban. This is consistent with the fact that these are the groups most likely to visit hospitality venues $^{12}$ and that women are more likely to show compliance to rules than men. ${ }^{13}$

\subsection{Seasonality in smoking behaviour}

Figures 1 to 3 offer clear evidence of a seasonal effect in smoking behaviour. Here we explore whether this effect is due to: New Year's resolutions, climate effects or price changes. ${ }^{14}$

First, we investigate the hypothesis that the March vs. December effect is due to New Year's resolutions. Typical examples of New Year's resolutions (besides quitting smoking) are "going on a diet", and "joining a gym" or starting some (heavier) form of physical exercise. We use information on diet and physical exercise available in the IHS. We construct a variable indicating whether an individual is on a diet (excluding a diet prescribed by a physician) and a variable which indicates whether the individual carries out regular physical exercise. We then estimate the effect of the ban on these two outcomes. The coefficient $\delta$ in equation (2) can be interpreted here as the New Year effect rather than post-ban effect. Estimates of the model in equation (1) show no significant changes in the prevalence of diet or physical exercises with the New Year. Only for women we find some evidence that they tend to practice more sport in March than in December. Using a DiD approach, like in equation (2), even this effect disappears.

Second, we check for the presence of climatic effects on smoking behaviour. Here we use data on average temperatures and rainfall by month and region. ${ }^{15}$ We find that these variables explain a substantial amount of seasonal variation in smoking behaviour. Substituting average temperature and rainfall for the ban variable in equation (1), we calculate that climate alone explains 50-80\% of the reduction in overall smoking prevalence and intensity that Buonanno and Ranzani (2013)

\footnotetext{
${ }^{12}$ In the IHS of 1999/2000 we find that among young people below the age of 40, not married or employed individuals are more likely to visit discos.

${ }^{13}$ For example, some studies have found that women show more tax compliance than men (see Kastlunger et al., 2010) and among pedestrians, males violate more rules than females (Tom and Granié, 2011).

${ }^{14}$ Results are not shown for reason of space, but are available from the authors on request.

${ }^{15}$ We use data of weather stations from capital cities of Italian provinces, i.e. administrative subdivisions of Italian regions, and calculate the regional means. The data are downloaded from http://www.ilmeteo.it/portale/archiviometeo.
} 
attributed to the smoking ban. ${ }^{16}$ The remaining $20-50 \%$ not explained by climate is consistent with the magnitude of our DiD estimates. As a further check, we add the two climatic variables to our DiD specifications (equation (2)). Our main findings do not change significantly. ${ }^{17}$ This check provides clear evidence that the climatic variables explain most of the observed seasonality in smoking behaviour, and that the DiD approach is able to capture it.

Finally, we consider whether changes in cigarettes prices might explain seasonal patterns in consumption. Cigarettes prices in Italy are regulated at the national level. Figure 4 reports the time series of cigarettes price over the period 1999-2007. We see sharp increases in real cigarettes prices, due to changes in excise duty, usually followed by gradual declines, due to inflationary pressure. As excise duty is usually set after the budget is announced, and this usually happens at the same time within each calendar year, changes in cigarettes prices could contribute to explain seasonal variation in smoking prevalence and consumption (Momperousse et al., 2007). However, because of Italy's rather irregular political cycle and multiple budget announcements within a year, we think that this is unlikely. Indeed, we see sharp changes in cigarettes prices at very irregular intervals. Large changes appear in July 1999, April 2001, April 2003, March 2004, December 2004, July 2005, February 2006, etc.; smaller increases are observed in January, June, August and December 2002, as well as December 2003, for example. So, it is very improbable that the seasonal pattern in smoking documented in Figures 1-3 is caused by changes in prices.

An important and related question, however, is whether sharp increases in cigarette prices might explain the observed differences in smoking prevalence and intensity between December 2004 and March 2005 observed in Buonanno and Ranzani (2013), and whether our DiD approach would give more robust estimate of the policy change in this case. As we can see from Figure 4, we observe a very large increase in cigarette prices in December 2004, with relatively small variation (mainly due to inflation) in the period up to June 2005. To the extent that smoking behaviour in December 2004 had not fully adjusted to the increase in prices (either as this occurred at the end of December

\footnotetext{
${ }^{16}$ In the short-term climate explains $70 \%$ of the reduction in overall smoking prevalence and $80 \%$ of the change in cigarette consumption; in the medium term $60 \%$ and $50 \%$, respectively. We find that rainfall has a statistically significant (and positive) impact on smoking, while average temperature has a negligible effect.

${ }^{17}$ We can identify the effects of temperatures and rainfall from the effect of the ban because the former vary by month and region while the ban only varies by month. In other words, this check relies on the assumption that the effect of the smoking ban is homogeneous across regions.
} 
or because of a lag in response), then the before/after estimates would confound the change in smoking behaviour due to the policy with the change due to price effects. Our DiD strategy would not be able to correct for this, as there is no corresponding increase in excise duty in December 1999.

This tells us two things. First, that the the difference between the DiD estimates and the before/after estimates cannot be attributed to the effect of variation in prices, but must be attributed to other factors such as variation in climatic conditions. Second, that the DiD estimates might still confound policy and price effects. However, since the DiD estimates are significantly different from zero only in some subgroups of the population, and particularly among individuals most likely to visit hospitality venues, we take this as evidence that our DiD estimates identify the true effect of the policy. ${ }^{18}$

\section{Conclusions}

Can smoke-free policies affecting public and work-places modify individual smoking behaviour? According to our reading of the existing evidence to date and the results of this study, the answer to this question is that these policies are at best able to affect the smoking prevalence and intensity of a relatively small group of the population in the short-term. Using a large sample of individuals, we show that the 2005 public smoking ban in Italy had negligible effects on the population as a whole while it reduced smoking prevalence by $8.4 \%$ and number of cigarettes smoked by $12.6 \%$ among young and not married individuals. We also show that the response was due mainly to changes in women's behaviour.

These results are in sharp contrast with several previous evaluations of the 2005 smoking ban in Italy (Buonanno and Ranzani, 2013; Cesaroni et al., 2008; Federico et al., 2012; Gallus et al., 2006; Gallus et al., 2007). We demonstrate that the results of these previous studies confound the effects of the policy with seasonal variation in smoking behaviour, as their empirical approach is based on before/after (January 2005) variation in smoking. Using data from the 1999/2000 wave of

\footnotetext{
${ }^{18}$ Alternatively, we can think that these subgroups are those with the highest elasticity of cigarettes consumption with respect to price, but we have found no evidence in the literature which would support this interpretation.
} 
the Italian Survey of Health to 'control' for the variation observed in 2004/2005, and implementing a difference-in-difference approach, we are able to net out seasonal variation in smoking behaviour and obtain estimates of the true impact of the reform.

Our study reveals the existence of a marked seasonal pattern in smoking behaviour. This pattern emerges from the analysis of individual data on smoking prevalence and consumption, as well as aggregate data on cigarette sales. We offer a comprehensive explanation of this phenomenon, investigating whether it might be due to tax increases, weather conditions or timing of quitting efforts (e.g., New Year's resolutions). We show that the most likely cause of seasonal changes in smoking is due to climatic variables, such as rainfall.

This analysis implies that previous evaluations of the effects of smoking regulations on either individual smoking behaviour or the health consequences of smoking behaviour (e.g., asthma exacerbations, birthweight, etc.), which are based on a before/after comparison, might lead to biased estimates of the effect of interest. More generally, in the absence of an adequately constructed control group, any policy evaluation exercise on outcomes that might exhibit seasonal variation (such as smoking, fertility, or the incidence of respiratory diseases) might lead to incorrect inference. 


\section{References}

Anger S., Kvasnicka M. and T. Siedler, 2011. "One last puff? Public smoking bans and smoking behavior," Journal of Health Economics 30(3): 591-601

Barnoya J., Bialous S.A. and S.A. Glant, 2005. "Effective interventions to reduce smoking-induced heart disease around the world: time to act," Circulation 112: 456-458

Barone-Adesi F., Vizzini L., Merletti F. and L. Richiardi, 2006. "Short-term effects of Italian smoking regulation on rates of hospital admission for acute myocardial infarction," European Heart Journal 27: 2468-72

Buonanno P. and M. Ranzani, 2013. "Thank you for not smoking: Evidence from the Italian smoking ban," Health Policy 109(2): 192-199.

Cesaroni G., Forastiere F., Agabiti N., Valente P., Zuccaro P. and C.A. Perucci, 2008. "Effect of the Italian smoking ban on population rates of acute coronary events," Circulation 117: 1183-8

Doll R., Peto R., Wheatley K., Gray R. and I. Sutherland, 1994. "Mortality in relation to smoking: 40 years' observations on male British doctors," British Medical Journal 309: 901-911

Elton P.J. and P. Campbell, 2008. "Smoking prevalence in a north-west town following the introduction of Smoke-free England," Journal of Public Health 30(4): 415-420

Evans W.N., Farelly M.C. and E. Montgomery, 1999. "Do workplace smoking bans reduce smoking?," American Economic Review 89(4): 728-747

Federico B., Mackenbach J.P., Eikemo T.A. and A.E. Kunst, 2012. "Impact of the 2005 smoke-free policy in Italy on prevalence, cessation and intensity of smoking in the overall population and by educational group," Addiction doi:10.1111/j.1360-0443.2012.03853.x

Fichtenberg C.M. and S.A. Glantz, 2000. "Association of the California Tobacco Control Program with declines in cigarette consumption and mortality from heart disease," New England Journal of Medicine 343: $1772-7$

Gallus S., Pacifici R., Colombo P., Scarpino V., Zuccaro P., Bosetti C. et al., 2004. "Prevalence of smoking and attitude towards smoking regulation in Italy," Eur J Cancer Prev 2006 15: 77-81

Gallus S., Zuccaro P., Colombo P., Apolone G., Pacifici R., Garattini S. and C. La Vecchia, 2006. "Effects of new smoking regulations in Italy," Ann Oncol 17: 346-7

Gallus S., Zuccaro P., Colombo P., Apolone G., Pacifici R., Garattini S. et al., 2007. "Smoking in Italy 2005-2006: Effects of a comprehensive national tobacco regulation," Preventive Medicine 45: 198-201

Gorini G., Gasparrini A., Fondelli M.C., Costantini A.S., Centrich F., Lopez M.J., Nebot M. and E. Tamang, 2005. "Environmental tobacco smoke (ETS) exposure in Florence hospitality venues before and after the smoking ban in Italy," J Occup Environ Med. 47: 1208-1210

Gorini G., 2011. "Impact of the Italian smoking ban and comparison with the evaluation of the Scottish ban," Epidemiol Prev. 35(3-4 Suppl 1): 4-18 
Guerrero F., Santonja F. J., and Villanueva R. J. , 2011. "Analysing the Spanish smoke-free legislation of 2006: a new method to quantify its impact using a dynamic model," International Journal of Drug Policy 22(4): 247-251

Juster H.R., Loomis B.R., Hinman T.M., Farrelly M.C., Hyland A., Bauer U.E. and G.S. Birkhead, 2007. "Declines in Hospital Admissions for Acute Myocardial Infarction in New York State After Implementation of a Comprehensive Smoking Ban" American Journal of Public Health 97(11): 2035-9.

Kastlunger, B., Dressler, S.G., Kirchler, E., Mittone, L., Voracek, M., 2010. "Sex Differences in Tax Compliance: Differentiating between Demographic Sex, Gender-Role Orientation, and Prenatal Masculinization (2D:4D)," Journal of Economic Psychology 31(4): 542-552

Law MR, Morris JK, Wald NJ., 1997. "Environmental tobacco smoke exposure and ischaemic heart disease: an evaluation of the evidence," British Medical Journal 315: 973-980

La Vecchia C., Garattini S., Colombo P., Scarpino V., 2001. "Attitudes towards smoking regulation in Italy," Lancet 358 (9277): 245

Lee J. T. , S. A. Glantz, and C. Millett, 2011. "Effect of smoke-free legislation on adult smoking behaviour in England in the 18 months following implementation," PLoS One 6(6), Article ID e20933

Mackay D.F., Haw S.J., and J.P. Pell, 2011. "Impact of Scottish smoke-free legislation on smoking quit attempts and prevalence," PLoS One 6, Article ID e26188

Mackay D.F., Nelson S.M., Haw S.J., and J.P. Pell, 2012. "Impact of Scotland's Smoke-Free Legislation on Pregnancy Complications: Retrospective Cohort Study," PLoS Medicine 9: e1001175

Momperousse, D., Delnevo, C.D. and Lewis, M.J., 2007. "Exploring the seasonality of cigarette smoking behaviour," Tobacco Control 16(1): 69-70.

Mullally B. J., B. A. Greiner, S. Allwright, G. Paul, and I. J. Perry, 2009. "The effect of the Irish smokefree workplace legislation on smoking among bar workers," European Journal of Public Health 19(2): 206-211

Pell JP, Haw S, Cobbe S, Newby DE, Pell ACH, Fischbacher C et al. 2008. "Smoke-free legislation and hospitalizations for acute coronary syndrome, " the New England Journal of Medicine 359: 482-91.

Raupach T., Schafer K., Konstantinides S., Andreas S., 2006. "Secondhand smoke as an acute threat for the cardiovascular system: a change in paradigm," Eur Heart $J$ 27: 386-392

Shiono P.H., Behrman R., 1995. "Low birth weight: analysis and recommendations, " Future Child 5: 4-18

Stapleton M., Howard-Thompson A., Georce C., Hoover R.M., Self T.H., 2011. "Smoking and Asthma," J Am Board Fam Med May-June 24(3): 313-322

Tramacere I, Gallus S, Zuccaro P, Colombo P, Rossi S, Boffetta P, La Vecchia C, 2009. "Socio-demographic variation in smoking habits: Italy, 2008." Prev Med, 48: 213-217

Tom, A.a., Granié, M.-A.b., 2011. "Gender differences in pedestrian rule compliance and visual search at signalized and unsignalized crossroads," Accident Analysis and Prevention 43(5): 1794-1801 
Verdonk-Kleinjan W. M. , M. J. Candel, R. A. Knibbe, M. C. Willemsen, and H. de Vries, 2011. "Effects of a workplace-smoking ban in combination with tax increases on smoking in the Dutch population," Nicotine and Tobacco Research 13: 412-418 
Figure 1: Mean smoking rates by month

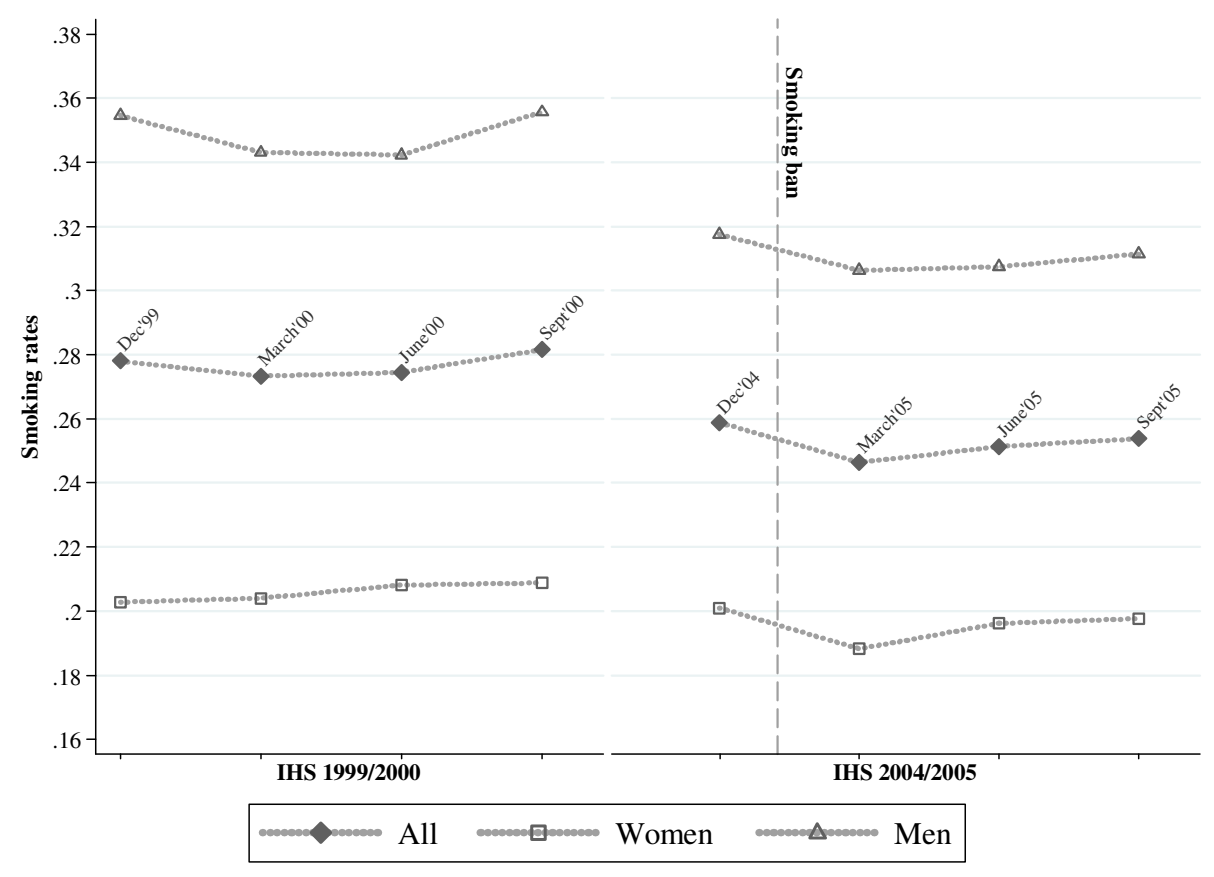

Source: IHS of 1999/2000 and 2004/2005. Sample restricted to individuals aged 15-65. 
Figure 2: Mean number of daily cigarettes by month

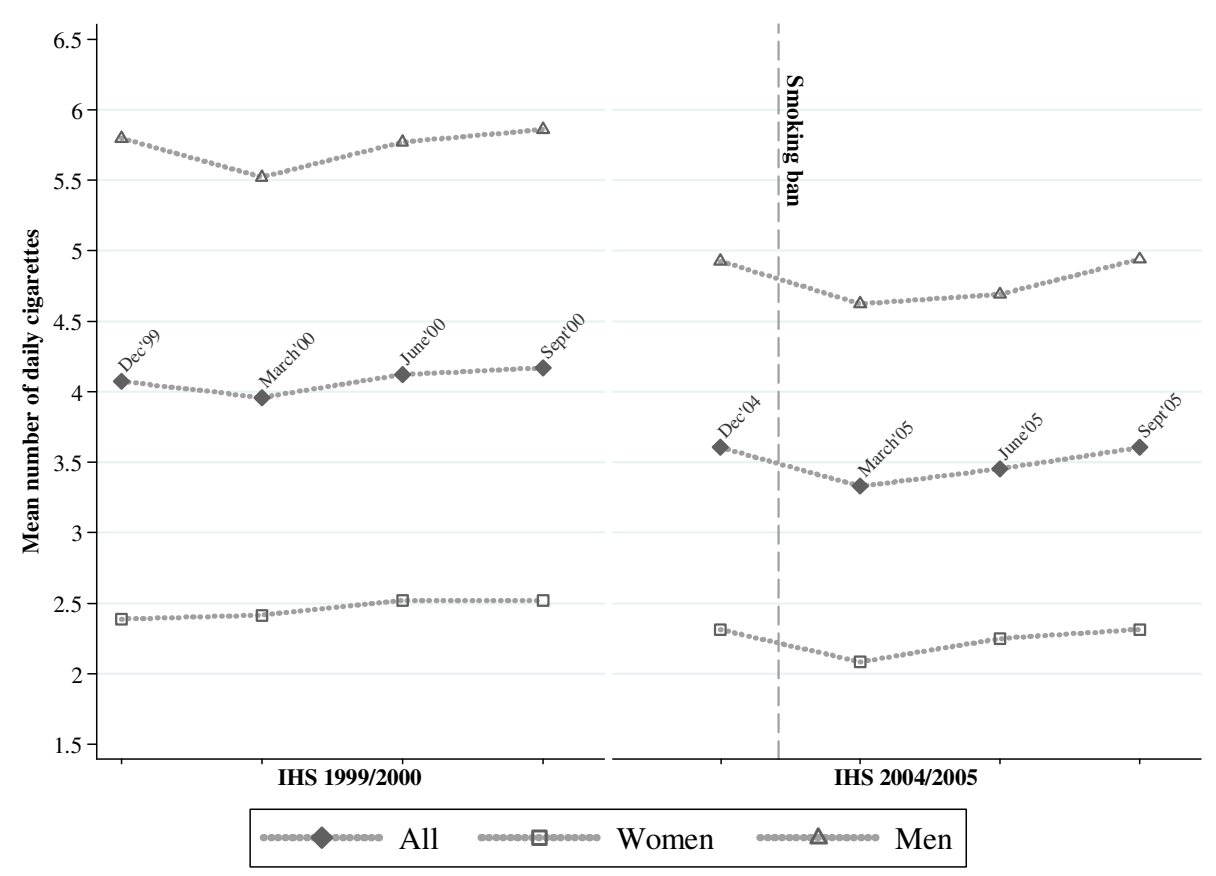

Source: IHS of 1999/2000 and 2004/2005. Sample restricted to individuals aged 15-65. Notes: The mean number of daily cigarettes is calculated for the overall sample, including non-smokers. 
Figure 3: Sales of cigarettes by month

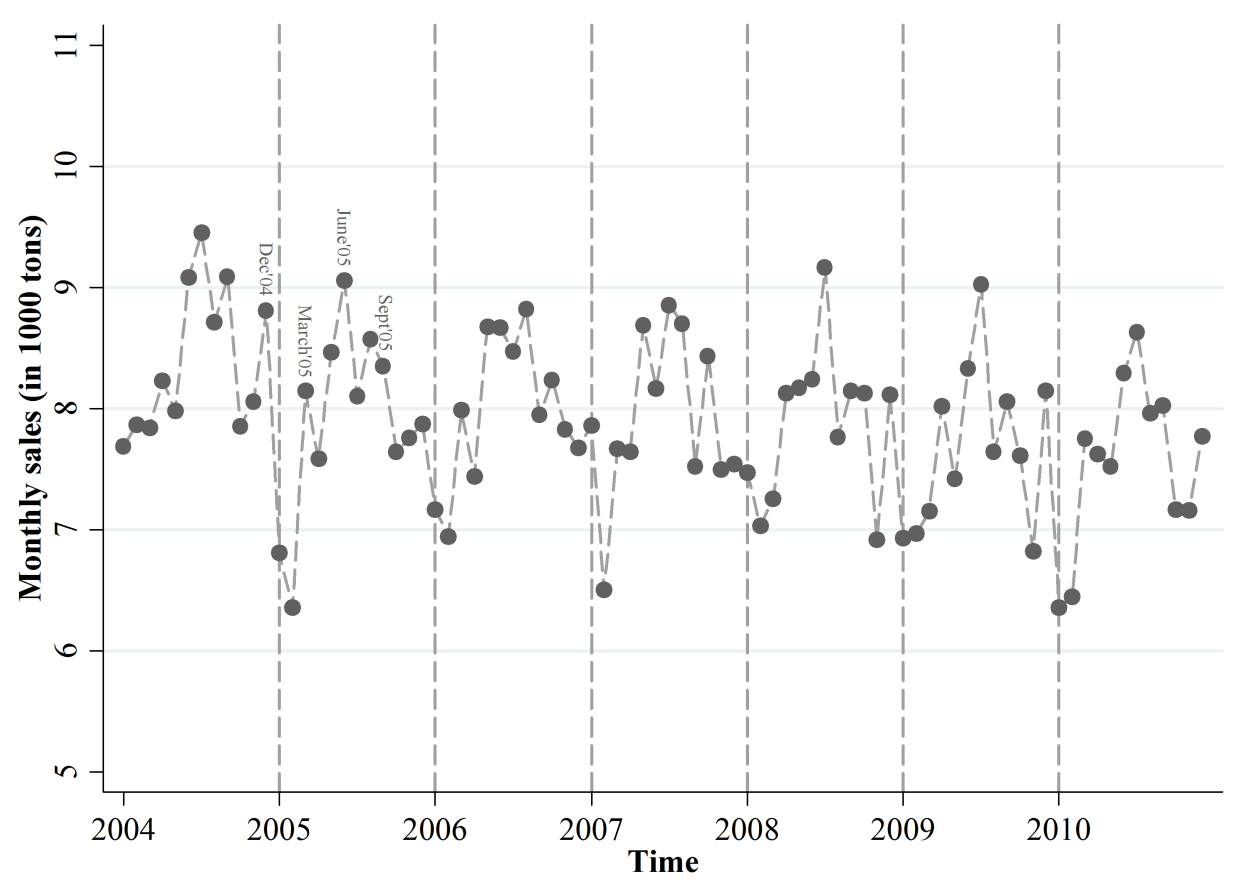

Source: ISTAT. Statistical Yearbooks (Annuario statistico italiano) 2004-2010. Notes: The figure includes the quantities of tobacco products transferred from the depositary warehouses to warehouses of distributors. 
Figure 4: Price of cigarettes

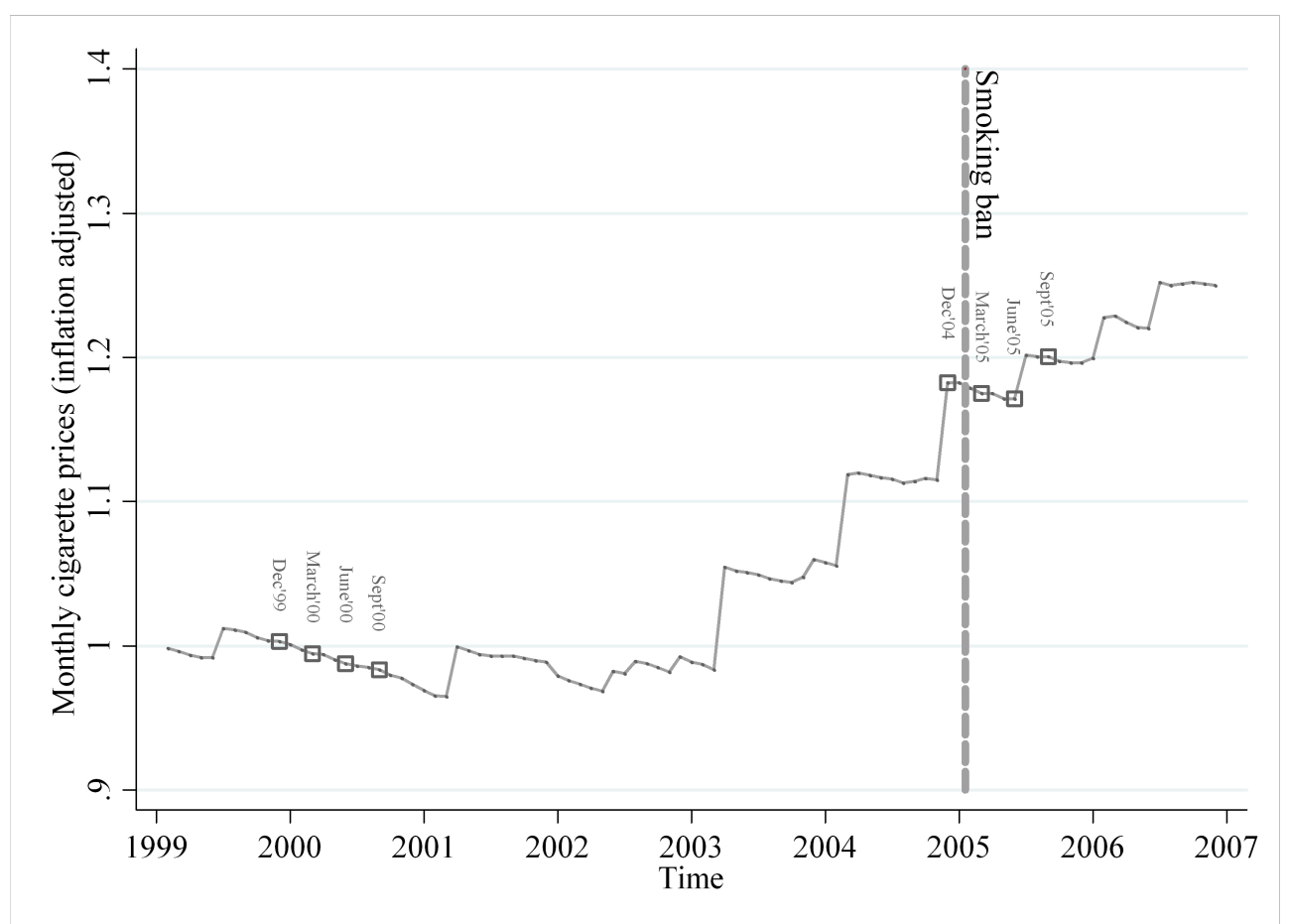

Source: ISTAT. Consumer Price Statistics (Servizio delle statistiche ai prezzi al consumo). Notes: Prices are inflation adjusted and normalized to the level of January 1999. 
Table 1: Summary statistics

\begin{tabular}{|l|c|c|c|c|c|c|c|c|}
\hline & \multicolumn{2}{|c|}{ \# of Obs. } & \multicolumn{2}{c|}{ \% of smokers } & \multicolumn{2}{c|}{ Cig. per capita } & \multicolumn{2}{c|}{ \% of 10+ Cig. } \\
\hline & $99 / 00$ & $04 / 05$ & $99 / 00$ & $04 / 05$ & $99 / 00$ & $04 / 05$ & $99 / 00$ & $04 / 05$ \\
\hline Dec. & 23,450 & 21,144 & 27.8 & 25.9 & 4.07 & 3.60 & 20.6 & 19.0 \\
Mar. & 23,283 & 21,111 & 27.3 & 24.6 & 3.96 & 3.33 & 20.3 & 17.7 \\
Jun. & 22,922 & 21,124 & 27.4 & 25.1 & 4.12 & 3.45 & 20.5 & 18.2 \\
Sep. & 24,198 & 21,240 & 28.2 & 25.4 & 4.17 & 3.60 & 20.9 & 18.7 \\
\hline Total & 93,853 & 84,619 & 27.7 & 25.3 & 4.08 & 3.49 & 20.6 & 18.4 \\
\hline
\end{tabular}

Source: IHS of 1999/2000 and 2004/2005. Sample restricted to 15-65 years old. 
Table 2: Smoking behaviour by subgroups

\begin{tabular}{|c|c|c|c|c|c|c|c|c|c|}
\hline & \multicolumn{3}{|c|}{ All } & \multicolumn{3}{|c|}{ Men } & \multicolumn{3}{|c|}{ Women } \\
\hline & Smoker $^{a}$ & $\# \mathrm{Cig}^{b}$ & Cig10+ ${ }^{c}$ & Smoker $^{a}$ & $\# \mathrm{Cig}^{b}$ & Cig10+ ${ }^{c}$ & Smoker $^{a}$ & $\# \mathrm{Cig}^{b}$ & Cig10+ ${ }^{c}$ \\
\hline \multirow[t]{2}{*}{ All } & 0.25 & 3.50 & 0.18 & 0.31 & 4.80 & 0.25 & 0.20 & 2.24 & 0.13 \\
\hline & $(0.43)$ & $(7.55)$ & $(0.39)$ & $(0.46)$ & $(8.87)$ & $(0.43)$ & $(0.40)$ & $(5.72)$ & $(0.33)$ \\
\hline \multirow[t]{2}{*}{ Married } & 0.23 & 3.42 & 0.18 & 0.30 & 4.93 & 0.24 & 0.18 & 2.05 & 0.12 \\
\hline & $(0.42)$ & $(7.65)$ & $(0.38)$ & $(0.46)$ & $(9.24)$ & $(0.43)$ & $(0.38)$ & $(5.49)$ & $(0.32)$ \\
\hline \multirow[t]{2}{*}{ Not married } & 0.28 & 3.60 & 0.19 & 0.33 & 4.64 & 0.25 & 0.22 & 2.51 & 0.14 \\
\hline & $(0.45)$ & $(7.41)$ & $(0.40)$ & $(0.47)$ & $(8.40)$ & $(0.43)$ & $(0.42)$ & $(6.02)$ & $(0.35)$ \\
\hline \multirow[t]{2}{*}{ North } & 0.25 & 3.28 & 0.17 & 0.29 & 4.25 & 0.22 & 0.21 & 2.33 & 0.13 \\
\hline & $(0.43)$ & $(7.27)$ & $(0.38)$ & $(0.46)$ & $(8.38)$ & $(0.41)$ & $(0.40)$ & $(5.83)$ & $(0.33)$ \\
\hline \multirow[t]{2}{*}{ Center } & 0.28 & 3.82 & 0.20 & 0.32 & 4.89 & 0.25 & 0.24 & 2.78 & 0.15 \\
\hline & $(0.45)$ & $(7.76)$ & $(0.40)$ & $(0.47)$ & $(8.88)$ & $(0.43)$ & $(0.43)$ & $(6.33)$ & $(0.36)$ \\
\hline \multirow[t]{2}{*}{ South } & 0.24 & 3.48 & 0.18 & 0.32 & 5.17 & 0.26 & 0.16 & 1.86 & 0.11 \\
\hline & $(0.43)$ & $(7.64)$ & $(0.39)$ & $(0.47)$ & $(9.22)$ & $(0.44)$ & $(0.37)$ & $(5.22)$ & $(0.31)$ \\
\hline \multirow[t]{2}{*}{ Low educated } & 0.26 & 3.93 & 0.20 & 0.34 & 5.54 & 0.28 & 0.19 & 2.33 & 0.13 \\
\hline & $(0.44)$ & $(8.07)$ & $(0.40)$ & $(0.47)$ & $(9.50)$ & $(0.45)$ & $(0.39)$ & $(5.91)$ & $(0.34)$ \\
\hline \multirow[t]{2}{*}{ High educated } & 0.24 & 3.01 & 0.16 & 0.28 & 3.93 & 0.21 & 0.20 & 2.15 & 0.12 \\
\hline & $(0.43)$ & $(6.88)$ & $(0.37)$ & $(0.45)$ & $(7.98)$ & $(0.40)$ & $(0.40)$ & $(5.51)$ & $(0.32)$ \\
\hline \multirow[t]{2}{*}{ Age 15-39 (Young) } & 0.26 & 3.19 & 0.18 & 0.32 & 4.50 & 0.24 & 0.19 & 1.89 & 0.11 \\
\hline & $(0.44)$ & $(6.87)$ & $(0.38)$ & $(0.47)$ & $(8.11)$ & $(0.43)$ & $(0.39)$ & $(5.03)$ & $(0.31)$ \\
\hline \multirow[t]{2}{*}{ Age $40-65$} & 0.25 & 3.78 & 0.19 & 0.30 & 5.07 & 0.25 & 0.20 & 2.55 & 0.14 \\
\hline & $(0.43)$ & $(8.10)$ & $(0.39)$ & $(0.46)$ & $(9.51)$ & $(0.43)$ & $(0.40)$ & $(6.25)$ & $(0.35)$ \\
\hline \multirow[t]{2}{*}{ Young\&Not marr. } & 0.26 & 3.12 & 0.17 & 0.32 & 4.09 & 0.23 & 0.20 & 1.97 & 0.11 \\
\hline & $(0.44)$ & $(6.63)$ & $(0.38)$ & $(0.46)$ & $(7.57)$ & $(0.42)$ & $(0.40)$ & $(5.11)$ & $(0.31)$ \\
\hline \multirow[t]{2}{*}{ Employed } & 0.29 & 4.24 & 0.22 & 0.34 & 5.31 & 0.27 & 0.23 & 2.62 & 0.15 \\
\hline & $(0.46)$ & $(8.18)$ & $(0.42)$ & $(0.47)$ & $(9.19)$ & $(0.44)$ & $(0.42)$ & $(6.01)$ & $(0.35)$ \\
\hline \multirow[t]{2}{*}{ Not employed } & 0.20 & 2.51 & 0.13 & 0.25 & 3.61 & 0.18 & 0.17 & 1.93 & 0.11 \\
\hline & $(0.40)$ & $(6.49)$ & $(0.34)$ & $(0.43)$ & $(7.97)$ & $(0.39)$ & $(0.37)$ & $(5.46)$ & $(0.31)$ \\
\hline \multirow[t]{2}{*}{ Young\&Not empl. } & 0.19 & 2.10 & 0.12 & 0.24 & 2.86 & 0.16 & 0.16 & 1.62 & 0.09 \\
\hline & $(0.39)$ & $(5.60)$ & $(0.32)$ & $(0.43)$ & $(6.57)$ & $(0.36)$ & $(0.37)$ & $(4.82)$ & $(0.29)$ \\
\hline
\end{tabular}

Source: IHS of 2004/2005. Sample restricted to $15-65$ years old. Notes: ${ }^{a}$ Ratio of smokers; ${ }^{b}$ Mean number of daily cigarettes per capita; ${ }^{c}$ Ratio of persons smoking 10 or more cigarettes per day. Standard deviations in parenthesis. The subgroup 'low educated' are people without a high school diploma.'High educated' are people who finished high school or college. The subgroups 'Young \& Not married' and 'Young \& Not employed' include individuals between age 15 and 39 who are also not married or not employed, respectively. 
Table 3: Replication - Before/after approach

\begin{tabular}{|c|c|c|c|c|c|c|c|c|c|}
\hline \multicolumn{10}{|c|}{ Panel A: Short-term estimates } \\
\hline & \multicolumn{3}{|c|}{ Buonanno et al.'s Results } & \multicolumn{3}{|c|}{ Replication Buonanno et al. } & \multicolumn{3}{|c|}{ Our Specification } \\
\hline & $\begin{array}{c}\text { Smoker } \\
\text { (1) }\end{array}$ & $\begin{array}{c}\text { \#Cig } \\
(2)\end{array}$ & $\begin{array}{c}\text { Cig10+ } \\
\text { (3) }\end{array}$ & $\begin{array}{c}\text { Smoker } \\
(4)\end{array}$ & $\begin{array}{c}\text { \#Cig } \\
(5)\end{array}$ & $\begin{array}{c}\text { Cig10+ } \\
\text { (6) }\end{array}$ & $\begin{array}{c}\text { Smoker } \\
(7)\end{array}$ & $\begin{array}{c}\text { \#Cig } \\
(8)\end{array}$ & $\begin{array}{c}\text { Cig10+ } \\
\text { (9) }\end{array}$ \\
\hline All & $\begin{array}{c}-.013^{* *} \\
(.005)\end{array}$ & $\begin{array}{c}-.271^{* *} \\
(.078)\end{array}$ & $\begin{array}{c}.013^{* *} \\
(.004)\end{array}$ & $\begin{array}{c}-.013^{* *} \\
(.005)\end{array}$ & $\begin{array}{c}-.270^{* *} \\
(.078)\end{array}$ & $\begin{array}{c}.013^{* *} \\
(.004)\end{array}$ & $\begin{array}{c}-.012^{* *} \\
(.005)\end{array}$ & $\begin{array}{c}.267^{* *} \\
(.080)\end{array}$ & $\begin{array}{c}.013^{* *} \\
(.004)\end{array}$ \\
\hline$N$ & 42,255 & 42,255 & 42,255 & 42,255 & 42,255 & 42,255 & 42,255 & 41,128 & 41,128 \\
\hline \multicolumn{10}{|l|}{ Subgroups: } \\
\hline Male & $\begin{array}{l}-.013 \\
(.007)\end{array}$ & $\begin{array}{c}-.330^{* *} \\
(.122)\end{array}$ & $\begin{array}{c}-.016^{* *} \\
(.006)\end{array}$ & $\begin{array}{l}-.013 \\
(.007)\end{array}$ & $\begin{array}{c}-.328^{* *} \\
(.122)\end{array}$ & $\begin{array}{c}-.015^{*} \\
(.006)\end{array}$ & $\begin{array}{l}-.012 \\
(.007)\end{array}$ & $\begin{array}{c}-.323^{* *} \\
(.124)\end{array}$ & $\begin{array}{l}-.015^{*} \\
(.006)\end{array}$ \\
\hline Female & $-.012^{*}$ & $-.214^{* *}$ & $-.011^{*}$ & $-.012^{*}$ & $-.213^{* *}$ & $-.011^{*}$ & $-.012^{*}$ & $-.215^{* *}$ & $-.011^{*}$ \\
\hline Married & $\begin{array}{r}-.017^{*} \\
(.007)\end{array}$ & $\begin{array}{c}-.291^{* *} \\
(.110)\end{array}$ & $\begin{array}{l}-.014^{*} \\
(.006)\end{array}$ & $\begin{array}{l}-.008 \\
(.006)\end{array}$ & $\begin{array}{l}-.237^{*} \\
(.103)\end{array}$ & $\begin{array}{l}-.010^{*} \\
(.005)\end{array}$ & $\begin{array}{l}-.007 \\
(.006)\end{array}$ & $\begin{array}{l}-.234^{*} \\
(.105)\end{array}$ & $\begin{array}{l}-.010 \\
(.005)\end{array}$ \\
\hline Not married & $\begin{array}{l}-.009 \\
(.006)\end{array}$ & $\begin{array}{l}-.252^{*} \\
(.103)\end{array}$ & $\begin{array}{l}-.012^{*} \\
(.005)\end{array}$ & $\begin{array}{c}-.018^{*} \\
(.007)\end{array}$ & $\begin{array}{c}-.303^{* *} \\
(.111)\end{array}$ & $\begin{array}{c}-.016^{* *} \\
(.006)\end{array}$ & $\begin{array}{l}-.018^{*} \\
(.007)\end{array}$ & $\begin{array}{c}-.306^{* *} \\
(.114)\end{array}$ & $\begin{array}{c}-.016^{* *} \\
(.006)\end{array}$ \\
\hline North & $\begin{array}{l}-.013 \\
(.008)\end{array}$ & $\begin{array}{l}-.240 \\
(.131)\end{array}$ & $\begin{array}{l}-.018^{*} \\
(.007)\end{array}$ & $\begin{array}{l}-.013 \\
(.008)\end{array}$ & $\begin{array}{l}-.239 \\
(.131)\end{array}$ & $\begin{array}{l}-.017^{*} \\
(.007)\end{array}$ & $\begin{array}{l}-.013 \\
(.008)\end{array}$ & $\begin{array}{l}-.255 \\
(.133)\end{array}$ & $\begin{array}{c}-.018^{* *} \\
(.007)\end{array}$ \\
\hline Center & $\begin{array}{l}-.006 \\
(.010)\end{array}$ & $\begin{array}{l}-.190 \\
(.166)\end{array}$ & $\begin{array}{l}-.004 \\
(.009)\end{array}$ & $\begin{array}{l}-.005 \\
(.010)\end{array}$ & $\begin{array}{l}-.185 \\
(.166)\end{array}$ & $\begin{array}{l}-.004 \\
(.009)\end{array}$ & $\begin{array}{l}-.006 \\
(.010)\end{array}$ & $\begin{array}{l}-.179 \\
(.170)\end{array}$ & $\begin{array}{l}-.003 \\
(.009)\end{array}$ \\
\hline South & $\begin{array}{l}-.016^{*} \\
(.007)\end{array}$ & $\begin{array}{c}-.335^{* *} \\
(.120)\end{array}$ & $\begin{array}{l}-.015^{*} \\
(.006)\end{array}$ & $\begin{array}{l}-.016^{*} \\
(.007)\end{array}$ & $\begin{array}{c}-.336^{* *} \\
(.120)\end{array}$ & $\begin{array}{l}-.015^{*} \\
(.006)\end{array}$ & $\begin{array}{l}-.015^{*} \\
(.007)\end{array}$ & $\begin{array}{c}-.325^{* *} \\
(.122)\end{array}$ & $\begin{array}{c}-.014^{*} \\
(.006)\end{array}$ \\
\hline \multicolumn{10}{|l|}{ Additional } \\
\hline $\begin{array}{l}\text { subgroups: } \\
\text { Low educated }\end{array}$ & & & & $\begin{array}{c}-.017^{* *} \\
(.006)\end{array}$ & $\begin{array}{c}-.310^{* *} \\
(.110)\end{array}$ & $\begin{array}{c}-.018^{* *} \\
(.006)\end{array}$ & $\begin{array}{c}-.017^{* *} \\
(.006)\end{array}$ & $\begin{array}{c}-.313^{* *} \\
(.112)\end{array}$ & $\begin{array}{c}-.018^{* *} \\
(.006)\end{array}$ \\
\hline High educated & & & & $\begin{array}{l}-.006 \\
(.006)\end{array}$ & $\begin{array}{l}-.185 \\
(.101)\end{array}$ & $\begin{array}{l}-.006 \\
(.005)\end{array}$ & $\begin{array}{l}-.006 \\
(.006)\end{array}$ & $\begin{array}{l}-.187 \\
(.104)\end{array}$ & $\begin{array}{l}-.006 \\
(.006)\end{array}$ \\
\hline Age $15-39$ & & & & $-.016^{*}$ & $-.259^{* *}$ & $-.012^{*}$ & $-.016^{*}$ & $-.260^{*}$ & $-.012^{*}$ \\
\hline Age $40-65$ & & & & $\begin{array}{l}.007) \\
-.009\end{array}$ & $\begin{array}{l}(.100) \\
-.282^{*}\end{array}$ & $\begin{array}{c}(.005) \\
-.014^{* *}\end{array}$ & $\begin{array}{l}(.006) \\
-.009\end{array}$ & $\begin{array}{l}(.102) \\
-.277^{*}\end{array}$ & $\begin{array}{l}(.006) \\
-.014^{*}\end{array}$ \\
\hline & & & & $(.006)$ & $(.111)$ & $(.005)$ & $(.006)$ & $(.112)$ & $(.006)$ \\
\hline Young\&Not marr. & & & & $-.022^{* *}$ & $-.358^{* *}$ & $-.017^{* *}$ & $-.022^{* *}$ & $-.365^{* *}$ & $-.017^{*}$ \\
\hline & & & & $(.008)$ & $(.117)$ & $(.007)$ & $(.008)$ & $(.119)$ & $(.007)$ \\
\hline Employed & & & & $-.014^{*}$ & $-.299^{* *}$ & $-.014^{*}$ & $-.014^{*}$ & $-.291^{* *}$ & $-.014^{*}$ \\
\hline & & & & $(.006)$ & $(.108)$ & $(.006)$ & $(.006)$ & $(.109)$ & $(.006)$ \\
\hline Not employed & & & & -.009 & $-.215^{*}$ & $-.011^{*}$ & -.009 & $-.224^{*}$ & $-.011^{*}$ \\
\hline & & & & $(.006)$ & $(.098)$ & $(.005)$ & $(.006)$ & $(.100)$ & $(.005)$ \\
\hline Young\&Not empl. & & & & -.013 & $-.256^{*}$ & -.011 & -.014 & $-.276^{*}$ & -.012 \\
\hline \multicolumn{10}{|c|}{ Panel B: Medium-term estimates } \\
\hline & \multicolumn{3}{|c|}{ Buonanno et al.'s Results } & \multicolumn{3}{|c|}{ Replication of Buonanno et al. } & \multicolumn{3}{|c|}{ Our Specification } \\
\hline & $\begin{array}{c}\text { Smoker } \\
\text { (1) }\end{array}$ & $\begin{array}{c}\text { \#Cig } \\
(2)\end{array}$ & $\begin{array}{c}\text { Cig10+ } \\
\text { (3) }\end{array}$ & $\begin{array}{c}\text { Smoker } \\
\text { (4) }\end{array}$ & $\begin{array}{c}\text { \#Cig } \\
(5)\end{array}$ & $\begin{array}{l}\text { Cig10+ } \\
\quad(6)\end{array}$ & $\begin{array}{c}\text { Smoker } \\
(7)\end{array}$ & $\begin{array}{c}\text { \#Cig } \\
(8)\end{array}$ & $\begin{array}{l}\text { Cig10+ } \\
\quad(9)\end{array}$ \\
\hline All & $\begin{array}{c}-.010^{* *} \\
(.004)\end{array}$ & $\begin{array}{c}-.178^{* *} \\
(.065)\end{array}$ & $\begin{array}{c}-.010^{* *} \\
(.003)\end{array}$ & $\begin{array}{c}-.010^{* *} \\
(.004)\end{array}$ & $\begin{array}{c}-.179^{* *} \\
(.064)\end{array}$ & $\begin{array}{c}-.010^{* *} \\
(.003)\end{array}$ & $\begin{array}{c}-.010^{* *} \\
(.004)\end{array}$ & $\begin{array}{c}-.168^{*} \\
(.066)\end{array}$ & $\begin{array}{c}-.010^{* *} \\
(.003)\end{array}$ \\
\hline$N$ & 84,619 & 84,619 & 84,619 & 84,619 & 84,619 & 84,619 & 84,619 & 82,333 & 82,333 \\
\hline
\end{tabular}

Source: IHS of 2004/2005. Sample restricted to 15-65 years old. Notes: Each number represents a separate estimate of the coefficient $\beta$ in equation (1), and indicates whether the individual was interviewed after the smoking ban came into effect. Panel A reports results of the short-term estimates, where we compare individuals interviewed in March 2005 versus those interviewed in December 2004; Panel B refers to medium-term estimates, obtained by comparing individuals interviewed in March, June and September 2005 versus those interviewed in December 2004. All estimates are performed using OLS and standard errors (in parentheses) are clustered at household level, with ${ }^{*} p<.05,{ }^{* *} p<.01$. Columns (1)-(3) report results of Table 2, 4 and 5 in Buonanno and Ranzani (2013). Columns (4)-(6) report the corresponding estimates based on our sample. The covariates include: age, age squared, household size, an indicator variables for being female, the presence of children of age below 8 in the household, indicator variables for being married, having a high school diploma, being employed, being inactive, having household economic conditions which are adequate or excellent, having a discrete, good or very good selfreported health status and a full set of regional dummies. Columns (7)-(9) report results based on our preferred specification, where we omit self-reported health and use a full set of dummy variables for educational attainment (elementary school or less, junior high school diploma, high school diploma and missing information on educational attainment). Additionally, in columns (8) and (9) we exclude from our sample individuals who smoke, but who do not provide valid information on the number of cigarettes smoked (these individuals are included in columns (2), (3), (5) and (6) with a value of 0 for number of cigarettes smoked). 
Table 4: Short-term Difference-in-Difference

\begin{tabular}{|c|c|c|c|c|c|c|c|c|c|}
\hline \multicolumn{10}{|c|}{ Short-term estimates } \\
\hline & \multicolumn{3}{|c|}{ All } & \multicolumn{3}{|c|}{ Men } & \multicolumn{3}{|c|}{ Women } \\
\hline & $\begin{array}{c}\text { Smoker } \\
\text { (1) }\end{array}$ & $\begin{array}{c}\text { \#Cig } \\
(2)\end{array}$ & $\begin{array}{c}\text { Cig10+ } \\
(3)\end{array}$ & $\begin{array}{c}\text { Smoker } \\
(4)\end{array}$ & $\begin{array}{c}\text { \#Cig } \\
(5)\end{array}$ & $\begin{array}{c}\text { Cig10+ } \\
\text { (6) }\end{array}$ & $\begin{array}{c}\text { Smoker } \\
(7)\end{array}$ & $\begin{array}{c}\text { \#Cig } \\
(8)\end{array}$ & $\begin{array}{c}\text { Cig10+ } \\
\text { (9) }\end{array}$ \\
\hline All & $\begin{array}{c}-.007 \\
(.007)\end{array}$ & $\begin{array}{c}-.137 \\
(.114)\end{array}$ & $\begin{array}{c}-.009 \\
(.006)\end{array}$ & $\begin{array}{l}-.003 \\
(.009)\end{array}$ & $\begin{array}{l}-.062 \\
(.178)\end{array}$ & $\begin{array}{c}-.007 \\
(.009)\end{array}$ & $\begin{array}{c}-.012 \\
(.008)\end{array}$ & $\begin{array}{l}-.225^{*} \\
(.112)\end{array}$ & $\begin{array}{l}-.012 \\
(.006)\end{array}$ \\
\hline$N$ & 88,988 & 87,722 & 87,722 & 44,112 & 43,344 & 43,344 & 44,876 & 44,378 & 44,378 \\
\hline Subg & & & & & & & & & \\
\hline Marr & $\begin{array}{l}-.000 \\
(.008)\end{array}$ & $\begin{array}{l}-.017 \\
(.150)\end{array}$ & $\begin{array}{l}-.003 \\
(.007)\end{array}$ & $\begin{array}{c}.001 \\
(.012)\end{array}$ & $\begin{array}{c}.076 \\
(.245)\end{array}$ & $\begin{array}{l}-.002 \\
(.011)\end{array}$ & $\begin{array}{l}-.002 \\
(.009)\end{array}$ & $\begin{array}{l}-.119 \\
(.137)\end{array}$ & $\begin{array}{l}-.004 \\
(.008)\end{array}$ \\
\hline Not married & $\begin{array}{l}-.016 \\
(.010)\end{array}$ & $\begin{array}{l}-.309 \\
(.160)\end{array}$ & $\begin{array}{l}-.018^{*} \\
(.009)\end{array}$ & $\begin{array}{l}-.009 \\
(.014)\end{array}$ & $\begin{array}{l}-.261 \\
(.246)\end{array}$ & $\begin{array}{l}-.014 \\
(.013)\end{array}$ & $\begin{array}{l}-.025^{*} \\
(.012)\end{array}$ & $\begin{array}{l}-.376^{*} \\
(.178)\end{array}$ & $\begin{array}{l}-.024^{*} \\
(.010)\end{array}$ \\
\hline North & $\begin{array}{l}-.009 \\
(.011)\end{array}$ & $\begin{array}{l}-.122 \\
(.192)\end{array}$ & $\begin{array}{l}-.017 \\
(.010)\end{array}$ & $\begin{array}{l}-.005 \\
(.015)\end{array}$ & $\begin{array}{l}-.166 \\
(.290)\end{array}$ & $\begin{array}{l}-.022 \\
(.014)\end{array}$ & $\begin{array}{l}-.014 \\
(.014)\end{array}$ & $\begin{array}{l}-.098 \\
(.202)\end{array}$ & $\begin{array}{l}-.012 \\
(.011)\end{array}$ \\
\hline Center & $\begin{array}{l}-.013 \\
(.014)\end{array}$ & $\begin{array}{l}-.330 \\
(.243)\end{array}$ & $\begin{array}{l}-.012 \\
(.013)\end{array}$ & $\begin{array}{l}.005 \\
(.019)\end{array}$ & $\begin{array}{l}-.034 \\
(.369)\end{array}$ & $\begin{array}{c}.012 \\
(.018)\end{array}$ & $\begin{array}{l}-.033 \\
(.017)\end{array}$ & $\begin{array}{l}-.627^{*} \\
(.254)\end{array}$ & $\begin{array}{l}-.035^{*} \\
(.015)\end{array}$ \\
\hline South & $\begin{array}{l}-.002 \\
(.010)\end{array}$ & $\begin{array}{l}-.046 \\
(.173)\end{array}$ & $\begin{array}{l}-.003 \\
(.009)\end{array}$ & $\begin{array}{l}-.004 \\
(.014)\end{array}$ & $\begin{array}{c}.011 \\
(.283)\end{array}$ & $\begin{array}{l}-.006 \\
(.014)\end{array}$ & $\begin{array}{l}.000 \\
(.011)\end{array}$ & $\begin{array}{l}-.115 \\
(.154)\end{array}$ & $\begin{array}{l}-.000 \\
(.009)\end{array}$ \\
\hline Low educated & $\begin{array}{l}-.014 \\
(.008)\end{array}$ & $\begin{array}{l}-.184 \\
(.155)\end{array}$ & $\begin{array}{c}-.016^{*} \\
(.008)\end{array}$ & $\begin{array}{l}-.017 \\
(.012)\end{array}$ & $\begin{array}{l}-.216 \\
(.248)\end{array}$ & $\begin{array}{l}-.023 \\
(.012)\end{array}$ & $\begin{array}{l}-.013 \\
(.010)\end{array}$ & $\begin{array}{l}-.183 \\
(.151)\end{array}$ & $\begin{array}{l}-.010 \\
(.009)\end{array}$ \\
\hline High educated & $\begin{array}{c}.002 \\
(.009)\end{array}$ & $\begin{array}{l}-.062 \\
(.155)\end{array}$ & $\begin{array}{l}-.001 \\
(.008)\end{array}$ & $\begin{array}{l}.015 \\
(.013)\end{array}$ & $\begin{array}{l}.119 \\
(.246)\end{array}$ & $\begin{array}{l}.011 \\
(.012)\end{array}$ & $\begin{array}{l}-.010 \\
(.012)\end{array}$ & $\begin{array}{l}-.255 \\
(.162)\end{array}$ & $\begin{array}{l}-.014 \\
(.010)\end{array}$ \\
\hline Age $15-39$ & $\begin{array}{c}-0.012 \\
(0.009)\end{array}$ & $\begin{array}{c}-0.197 \\
(0.143)\end{array}$ & $\begin{array}{c}-0.012 \\
(0.008)\end{array}$ & $\begin{array}{l}-0.009 \\
(0.013)\end{array}$ & $\begin{array}{l}-0.139 \\
(0.227)\end{array}$ & $\begin{array}{c}-0.011 \\
(0.012)\end{array}$ & $\begin{array}{c}-0.016 \\
(0.011)\end{array}$ & $\begin{array}{c}-0.291^{*} \\
(0.145)\end{array}$ & $\begin{array}{c}-0.014 \\
(0.009)\end{array}$ \\
\hline Age $40-65$ & $\begin{array}{c}-0.003 \\
(0.009)\end{array}$ & $\begin{array}{l}-0.069 \\
(0.163)\end{array}$ & $\begin{array}{c}-0.007 \\
(0.008)\end{array}$ & $\begin{array}{c}0.001 \\
(0.012)\end{array}$ & $\begin{array}{l}-0.013 \\
(0.263)\end{array}$ & $\begin{array}{c}-0.005 \\
(0.012)\end{array}$ & $\begin{array}{l}-0.007 \\
(0.010)\end{array}$ & $\begin{array}{c}-0.139 \\
(0.160)\end{array}$ & $\begin{array}{l}-0.010 \\
(0.009)\end{array}$ \\
\hline Young\&Not marr. & $\begin{array}{c}-0.022^{*} \\
(0.011)\end{array}$ & $\begin{array}{c}-0.392^{*} \\
(0.168)\end{array}$ & $\begin{array}{c}-0.021^{*} \\
(0.009)\end{array}$ & $\begin{array}{l}-0.018 \\
(0.015)\end{array}$ & $\begin{array}{l}-0.341 \\
(0.253)\end{array}$ & $\begin{array}{c}-0.019 \\
(0.014)\end{array}$ & $\begin{array}{c}-0.029^{*} \\
(0.014)\end{array}$ & $\begin{array}{c}-0.485^{* *} \\
(0.185)\end{array}$ & $\begin{array}{l}-0.025^{*} \\
(0.011)\end{array}$ \\
\hline Employed & $\begin{array}{c}-0.002 \\
(0.009)\end{array}$ & $\begin{array}{l}-0.019 \\
(0.164)\end{array}$ & $\begin{array}{c}-0.006 \\
(0.008)\end{array}$ & $\begin{array}{c}0.007 \\
(0.011)\end{array}$ & $\begin{array}{c}0.170 \\
(0.225)\end{array}$ & $\begin{array}{c}0.002 \\
(0.011)\end{array}$ & $\begin{array}{c}-0.016 \\
(0.013)\end{array}$ & $\begin{array}{l}-0.318 \\
(0.186)\end{array}$ & $\begin{array}{l}-0.020 \\
(0.011)\end{array}$ \\
\hline Not employed & $\begin{array}{l}-0.011 \\
(0.008)\end{array}$ & $\begin{array}{l}-0.247 \\
(0.137)\end{array}$ & $\begin{array}{c}-0.012 \\
(0.007)\end{array}$ & $\begin{array}{l}-0.020 \\
(0.015)\end{array}$ & $\begin{array}{l}-0.519 \\
(0.276)\end{array}$ & $\begin{array}{c}-0.026 \\
(0.013)\end{array}$ & $\begin{array}{l}-0.008 \\
(0.009)\end{array}$ & $\begin{array}{l}-0.141 \\
(0.135)\end{array}$ & $\begin{array}{l}-0.006 \\
(0.008)\end{array}$ \\
\hline Young\&Not empl. & $\begin{array}{c}-0.021 \\
(0.012)\end{array}$ & $\begin{array}{c}-0.347^{*} \\
(0.171)\end{array}$ & $\begin{array}{c}-0.018 \\
(0.010)\end{array}$ & $\begin{array}{l}-0.024 \\
(0.020)\end{array}$ & $\begin{array}{l}-0.363 \\
(0.315)\end{array}$ & $\begin{array}{c}-0.027 \\
(0.017)\end{array}$ & $\begin{array}{c}-0.022 \\
(0.014)\end{array}$ & $\begin{array}{c}-0.414^{*} \\
(0.182)\end{array}$ & $\begin{array}{c}-0.018 \\
(0.011)\end{array}$ \\
\hline
\end{tabular}

Source: IHS of 1999/2000 and 2004/2005. Sample restricted to 15-65 years old. Notes: Each number represents a separate estimate of the coefficient $\delta$ in equation (2), which captures the effect of the ban net of seasonal effects. Estimates refer to short-term effects, obtained by comparing individuals interviewed in March versus those interviewed in December. All estimates are performed using OLS and standard errors (in parentheses) are clustered at household level, with ${ }^{*} p<.05,{ }^{* *} p<.01$. For main covariates see notes to Table 3 . 
Table 5: Medium-term Difference-in-Difference

\begin{tabular}{|c|c|c|c|c|c|c|c|c|c|}
\hline \multicolumn{10}{|c|}{ Medium-term estimates } \\
\hline & \multicolumn{3}{|c|}{ All } & \multicolumn{3}{|c|}{ Men } & \multicolumn{3}{|c|}{ Women } \\
\hline & $\begin{array}{c}\text { Smoker } \\
(1)\end{array}$ & $\begin{array}{c}\text { \#Cig } \\
(2)\end{array}$ & $\begin{array}{c}\text { Cig10+ } \\
\text { (3) }\end{array}$ & $\begin{array}{c}\text { Smoker } \\
(4)\end{array}$ & $\begin{array}{c}\text { \#Cig } \\
(5)\end{array}$ & $\begin{array}{c}\text { Cig10+ } \\
\text { (6) }\end{array}$ & $\begin{array}{c}\text { Smoker } \\
(7)\end{array}$ & $\begin{array}{c}\text { \#Cig } \\
(8)\end{array}$ & $\begin{array}{c}\text { Cig10+ } \\
(9)\end{array}$ \\
\hline All & $\begin{array}{l}-.008 \\
(.005)\end{array}$ & $\begin{array}{l}-.174 \\
(.094)\end{array}$ & $\begin{array}{l}-.009 \\
(.005)\end{array}$ & $\begin{array}{l}-.005 \\
(.007)\end{array}$ & $\begin{array}{l}-.140 \\
(.147)\end{array}$ & $\begin{array}{l}.008 \\
(.007)\end{array}$ & $\begin{array}{l}-.011 \\
(.006)\end{array}$ & $\begin{array}{l}-.205^{*} \\
(.093)\end{array}$ & $\begin{array}{l}-.010 \\
(.005)\end{array}$ \\
\hline$N$ & 178,472 & 175,892 & 175,892 & 88,391 & 86,793 & 86,793 & 90,081 & 89,099 & 89,099 \\
\hline \multicolumn{10}{|l|}{ Subgroups: } \\
\hline Married & $\begin{array}{l}-.000 \\
(.007)\end{array}$ & $\begin{array}{l}-.029 \\
(.124)\end{array}$ & $\begin{array}{l}-.002 \\
(.006)\end{array}$ & $\begin{array}{c}.001 \\
(.010)\end{array}$ & $\begin{array}{l}-.004 \\
(.203)\end{array}$ & $\begin{array}{l}-.002 \\
(.009)\end{array}$ & $\begin{array}{l}-.001 \\
(.008)\end{array}$ & $\begin{array}{l}-.058 \\
(.114)\end{array}$ & $\begin{array}{l}-.003 \\
(.007)\end{array}$ \\
\hline \multirow[t]{2}{*}{ Not married } & $-.018^{*}$ & $-.371^{* *}$ & $-.018^{* *}$ & -.011 & -.312 & -.015 & $-.026^{*}$ & $-.420^{* *}$ & $-.021^{*}$ \\
\hline & $(.008)$ & $(.132)$ & $(.007)$ & $(.011)$ & $(.203)$ & $(.010)$ & $(.010)$ & $(.148)$ & $(.009)$ \\
\hline \multirow[t]{2}{*}{ North } & -.010 & -.082 & -.012 & -.008 & -.198 & -.019 & -.012 & .022 & -.005 \\
\hline & $(.009)$ & $(.157)$ & $(.008)$ & $(.013)$ & $(.238)$ & $(.012)$ & $(.011)$ & $(.167)$ & $(.009)$ \\
\hline \multirow[t]{2}{*}{ Center } & -.010 & -.375 & -.011 & -.002 & -.299 & -.001 & -.018 & $-.448^{*}$ & -.022 \\
\hline & $(.011)$ & $(.199)$ & $(.010)$ & $(.016)$ & $(.307)$ & $(.015)$ & $(.014)$ & $(.208)$ & $(.012)$ \\
\hline \multirow[t]{2}{*}{ South } & -.006 & -.134 & -.006 & -.003 & .006 & -.003 & -.008 & -.247 & -.008 \\
\hline & $(.008)$ & $(.143)$ & $(.007)$ & $(.011)$ & $(.233)$ & $(.011)$ & $(.009)$ & $(.131)$ & $(.008)$ \\
\hline \multirow[t]{2}{*}{ Low educated } & $-.020^{* *}$ & $-.299^{*}$ & $-.019^{* *}$ & -.019 & -.282 & $-.022^{*}$ & $-.021^{* *}$ & $-.317^{*}$ & $-.015^{*}$ \\
\hline & $(.007)$ & $(.127)$ & $(.006)$ & $(.010)$ & $(.205)$ & $(.010)$ & $(.008)$ & $(.125)$ & $(.007)$ \\
\hline \multirow[t]{2}{*}{ High educated } & .008 & .012 & .004 & .014 & .066 & .010 & .002 & -.051 & -.003 \\
\hline & $(.008)$ & $(.128)$ & $(.007)$ & $(.011)$ & $(.203)$ & $(.010)$ & $(.010)$ & $(.135)$ & $(.008)$ \\
\hline \multirow[t]{2}{*}{ Age $15-39$} & -.012 & $-.260^{*}$ & -.012 & -.010 & -.179 & -.010 & -.014 & $-.343^{* *}$ & -.013 \\
\hline & $(.007)$ & $(.118)$ & $(.006)$ & $(.011)$ & $(.188)$ & $(.010)$ & $(.009)$ & $(.120)$ & $(.007)$ \\
\hline \multirow[t]{2}{*}{ Age 40-65 } & -.004 & -.081 & -.006 & -.001 & -.112 & -.006 & -.008 & -.062 & -.006 \\
\hline & $(.007)$ & $(.135)$ & $(.006)$ & $(.010)$ & $(.218)$ & $(.010)$ & $(.008)$ & $(.133)$ & $(.007)$ \\
\hline \multirow[t]{2}{*}{ Young\&Not marr. } & $-.023^{*}$ & $-.435^{* *}$ & $-.020^{*}$ & -.017 & -.319 & -.015 & $-.029^{*}$ & $-.577^{* *}$ & $-.026^{* *}$ \\
\hline & $(.009)$ & $(.139)$ & $(.008)$ & $(.012)$ & $(.209)$ & $(.011)$ & $(.012)$ & $(.154)$ & $(.009)$ \\
\hline \multirow[t]{2}{*}{ Employed } & -0.001 & -0.039 & -0.004 & 0.003 & 0.016 & -0.001 & -0.006 & -0.136 & -0.010 \\
\hline & $(0.007)$ & $(0.135)$ & $(0.007)$ & $(0.009)$ & $(0.186)$ & $(0.009)$ & $(0.010)$ & $(0.155)$ & $(0.009)$ \\
\hline \multirow[t]{2}{*}{ Not employed } & $-0.015^{*}$ & $-0.293^{* *}$ & $-0.013^{*}$ & -0.018 & -0.423 & -0.021 & -0.014 & $-0.229^{*}$ & -0.009 \\
\hline & $(0.007)$ & $(0.112)$ & $(0.006)$ & $(0.012)$ & $(0.228)$ & $(0.011)$ & $(0.008)$ & $(0.112)$ & $(0.006)$ \\
\hline \multirow[t]{2}{*}{ Young\&Not empl. } & $-0.024^{*}$ & $-0.484^{* *}$ & $-0.019^{*}$ & -0.023 & -0.391 & -0.022 & $-0.027^{*}$ & $-0.567^{* *}$ & $-0.020^{*}$ \\
\hline & $(0.010)$ & $(0.142)$ & $(0.008)$ & $(0.016)$ & $(0.260)$ & $(0.014)$ & $(0.011)$ & $(0.154)$ & $(0.009)$ \\
\hline
\end{tabular}

Source: IHS of 1999/2000 and 2004/2005. Sample restricted to 15-65 years old. Notes: Each number represents a separate estimate of the coefficient $\delta$ in equation (2), which captures the effect of the ban net of seasonal effects. Estimates refer to medium-term effects, obtained by comparing individuals interviewed in March, June and September versus those interviewed in December. All estimates are performed using OLS and standard errors (in parentheses) are clustered at household level, with ${ }^{*} p<.05,{ }^{* *} p<.01$. For main covariates see notes to Table 3. 